\title{
РОЛЬ ГЕОПОРТАЛОВ В УПРАВЛЕНИИ ЗЕМЕЛЬНО-ИМУЩЕСТВЕННЫМ ФОНДОМ МУНИЦИПАЛЬНЫХ ОБРАЗОВАНИЙ
}

\section{Елена Дмитриевна Соловьева}

Сибирский государственный университет геосистем и технологий, 630108, Россия, г. Новосибирск, ул. Плахотного, 10, обучающийся, тел. (923)121-88-97, e-mail: lena_97_11@list.ru

\section{Наталья Олеговна Митрофанова}

Сибирский государственный университет геосистем и технологий, 630108, Россия, г. Новосибирск, ул. Плахотного, 10, кандидат технических наук, доцент кафедры кадастра и территориального планирования, тел. (383)361-01-09, e-mail: north-easter@yandex.ru

Данная статья посвящена оценке геопорталов с точки зрения их использования в управлении земельно-имущественным фондом муниципальных образований. В статье рассмотрено назначение геопорталов для земельно-имущественного фонда муниципальных образований.

Проведен аналитический обзор геопорталов, их функциональные возможности и назначение в управлении земельно-имущественным фондом.

Произведена оценка геопорталов муниципальных образований РФ по основным показателям, где сравнивается г. Новосибирск с другими городами РФ.

Ключевые слова: геопорталы, муниципальные образования, земельно-имущественные отношения, метаданные, земельные участки, инфраструктура пространственных данных, инвестиционная привлекательность участков

\section{THE ROLE OF GEOPORTALS IN THE MANAGEMENT OF THE LAND AND PROPERTY FUND OF MUNICIPALITIES}

\section{Elena D. Solovyeva}

Siberian State University of Geosystems and Technologies, 10, Plakhotnogo St., Novosibirsk, 630108, Russia, Student, phone: (923)121-88-97, e-mail: lena_97_11@list.ru

\section{Natalia O. Mitrofanova}

Siberian State University of Geosystems and Technologies, 10, Plakhotnogo St., Novosibirsk, 630108, Russia, Ph. D., Associate Professor, Department of Cadastre and Territorial Planning, phone: (383) 344-31-73, e-mail: kadastr-204@yandex.ru

This article is devoted to the assessment of geoportals from the point of view of their use within the framework of the land and property fund of municipalities. The article considers the purpose of geoportals for the land and property fund of municipalities.

An analytical review of geoportals, their functionality and purpose in the management of land and property fund was carried out.

An assessment of the geoportals of municipalities of the Russian Federation was made according to the main indicators, where the city of Novosibirsk is compared with other cities of the Russian Federation.

Keywords: geoportals, municipalities, land and property relations, metadata, land plots, spatial data infrastructure, investment attractiveness of land plots 
На сегодняшний день геопорталы играют важную роль в формировании имиджа муниципального образования, создании инвестиционно привлекательного климата. В области земельно-имущественных отношений геопорталы направлены на эффективное и оперативное получение информации заинтересованными лицами об объектах недвижимости, особенностей той или иной территории, ускоряют процесс предоставления земельных участков в собственность или аренду гражданам и юридическим лицам.

Появление и развитие геопорталов связано с развитием сети Интернет. Однако, поскольку геопорталы обладают высокой функциональностью, интерактивным пользовательским интерфейсом, более быстрыми темпами они стали развиваться только с момента увеличения функциональных возможностей сети интернет.

Впервые концепция геопортала была сформулирована в рамках национальной инфраструктуры пространственных данных (ИПД) США (NSDI Clearinghouse Network). C середины девяностых годов появлялись Национальные геопорталы. В 2006 г. Правительством РФ принята «Концепция создания и развития ИПД Российской Федерации», а в 2012 г. в Росреестре запущен в опытно-промышленную эксплуатацию Геопортал ИПД РФ.

Геопортал-это программно-технологическое обеспечение для работы с ПД. Основной задачей является предоставление пользователю инструментов и сервисов для хранения и каталогизации, публикации и загрузки пространственных (географических) данных, поиска и фильтрации по метаданным, интерактивной веб-визуализации, прямого доступа к геоданным на основе картографических веб-сервисов [1].

Структура геопортала - это совокупность слоев, содержащих различную пространственную информацию. Информация на геопортале собрана с официальных источников и получена в результате полевых работ на местности. Геопортал-это цифровые и топографические карты открытого пользования, которые включают в себя множество слоев (объекты особо охраняемых территорий, здания (сооружения), дорожная сеть, гидрография, использование земель и т.д.).

Средства для пользователей геопортала: получать актуальную и постоянно обновляемую информацию о местности, отражающей полную и реальную ситуацию во всем регионе. Например, геопортал предоставляет возможность просматривать участки сгоревших и вырубленных лесов (за разные периоды времени в определенном районе районе), свалки ТБО, активные участки береговых процессов и доступность автодорог и др.

Геопорталы - важное и эффективное средство использования ГИС и ключевой элемент ИПД, которые основаны на концепции ИПД России, утвержденной распоряжением Правительства РФ от 21.08.2006 № 1157-р.

На рис. 1 представлена классификации порталов на основе доступности, функциональности и территориального охвата. 
По территориальному охвату

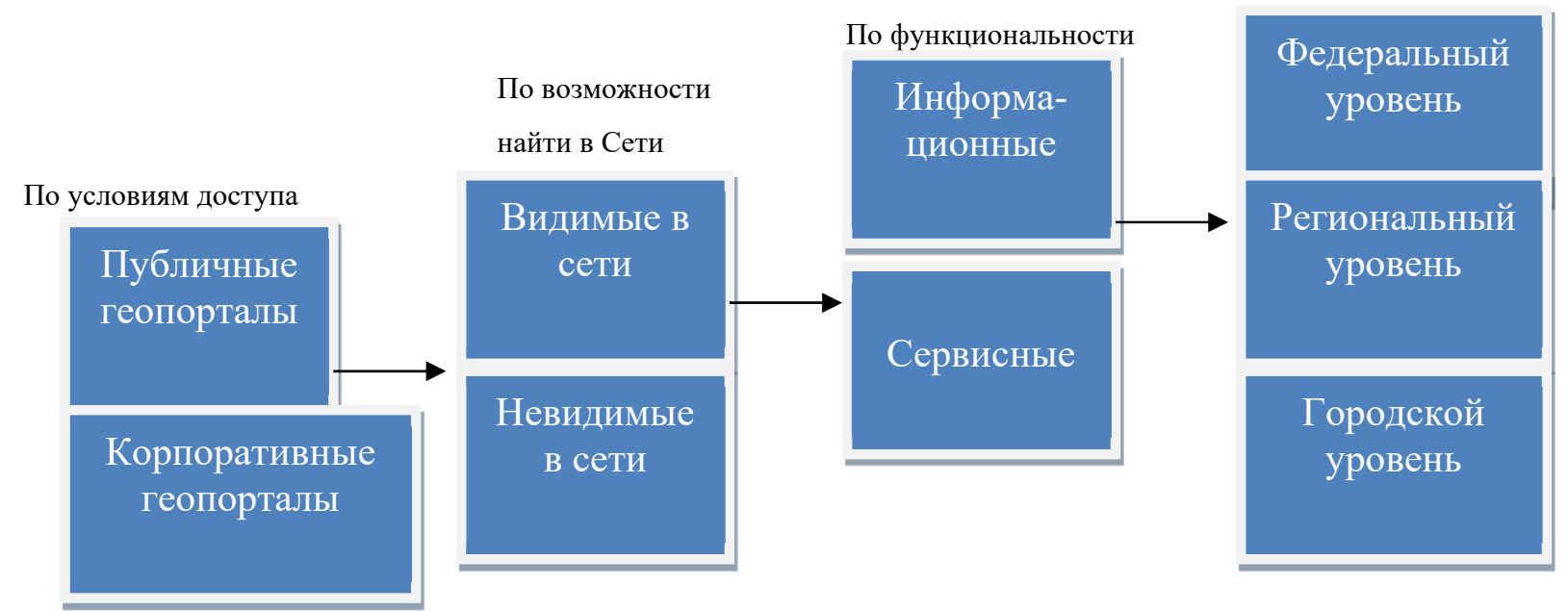

Рис. 1. Схема классификации порталов на основе доступности, функциональности и территориального охвата

Основными функциональными возможностями геопорталов являются:

- обеспечение каталога метаданных для поиска геоинформационных ресурсов по ключевым словам, тематике, расположению и другим критериям;

- анализ найденных ресурсов по отображению описаний;

- доступ к данным по путям, указанным в описаниях;

- картографическая визуализация;

- добавление пользователями личных метаданных в каталог;

- обмен информацией с другими геопорталами;

- предоставление программного интерфейса для реализации элементов геопортала на внешних сайтах;

- интеграция с программными пакетами ГИС.

Наиболее активно развиваются геопорталы в европейских странах, которые приняли директиву INSPIRE (Infrastructure for Spatial Informationin the European Community) - единые стандарты и механизмы взаимодействия различных субъектов при создании геоинформационных систем и работе с пространственными данными.

Следует отметить, что геопорталы в РФ обычно представлены в виде картографических веб-сервисов, облегчающих работу органов государственной власти субъектов РФ, но не являются хранилищами метаданных, как это принято в мире [2].

Цель создания геоинформационного портала как составной части геоинформационной системы органов государственной власти или государственного ведомства (учреждения) является разработка единого геоинформационного пространства с объединением базы данных министерств, ведомств и других органов 
управления различного подчинения (федеральных, республиканских, муниципальных) в единую среду пользования.

В рамках создания ГИС-портала решаются следующие задачи:

- анализ текущих источников геоинформационных данных;

- организация доступа к ПД;

- подбор оптимальных форматов для представления геоданных;

- разработка программного и аппаратного обеспечения, включая разработку клиентских приложений на основе веб-технологий.

Рассмотрим минимальные критерии поиска геопорталов:

- ключевые слова;

- классификаторами ПД и сервисов;

- пространственный охват;

- временной охват и возможность поиска данных;

- по названию административных органов, ответственных за создание, управление, обслуживание и распространение набора информации ПД и функционирование геосервисов и д.р.

Для иллюстрации функций поиска можно обратиться к геопорталу АИС ТП г. Новосибирск (http://gis.novo-sibirsk.ru). Посетителям геопортала на стартовой странице (рис. 2) предлагается воспользоваться поиском, выбрать слои и инструменты геопортала, а также обратиться за помощью к сотрудникам геопортала.

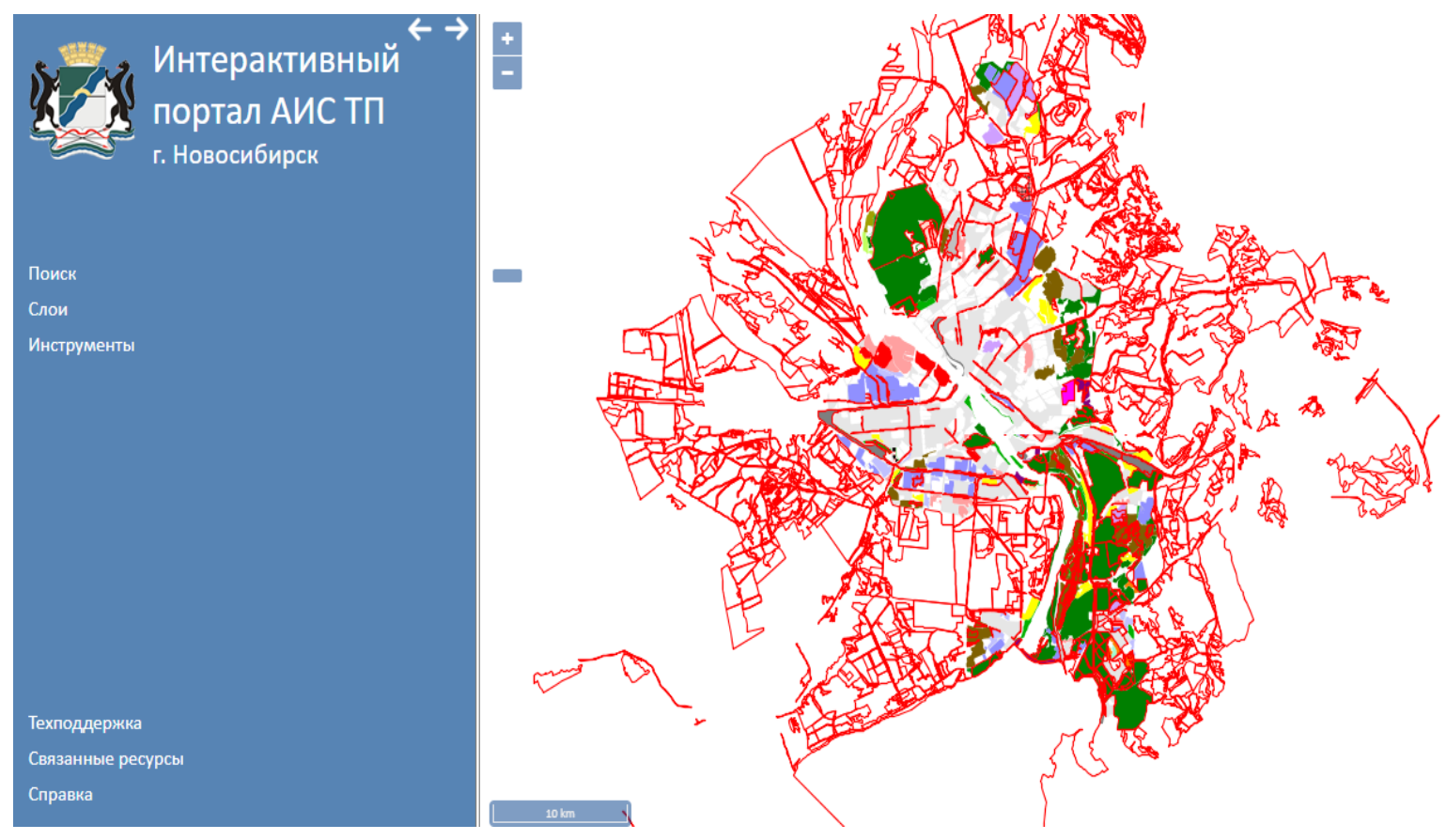

Рис. 2. Интерактивный портал АИС ТП г. Новосибирск

Функция поиска основана на метаописании записи данных. Метаданные могут быть подготовлены на рабочем месте поставщика данных и опубликованы или регистрированы непосредственно на геопортале-это функция 
системы или подсистемы управления метаданными, которая включает базу данных метаданных. Именно с их помощью заказчик может искать данные, отвечающие его запросу [9].

В 2005 г. в России был создан одноименный национальный профиль в виде стандарта ГОСТ Р 52573-2006 «Географическая информация. Метаданные». Стандарт был утвержден в середине 2006 г. и вступил в силу 1 января 2007 г. Он известен в нескольких реализациях, включая академический профиль «ГеоMETA» [2]. На основе ГОСТ Р 52573-2006 создана подсистема управления метаданными в составе Банка ПД Уральского федерального округа [1] и картографический портал ФГУП «Госгисцентр» (http:/www.ggc.ru).

Визуализация картографических данных, которая должна поддерживаться Web-картой геопортала, выбирается методом картографического изображения, его функцией управления, легендой, а также функцией обработки изображения и обработки легенд. Традиционно существует 12 методов картографического изображения, однако не все используются в инструментах ГИС, и лишь немногие из них используются в Web-картографических инструментах.

Для анализа качественной характеристики отечественных геопорталов было выполнено сравнение нескольких геопорталов муниципальных образований по нескольким основным факторам. Результаты представлены в таблице [3-8].

В идеальном представлении в каждом муниципальном образовании должен быть реализован проект создания единой многоцелевой геоинформационной системы, посредством которой обеспечивается сбор, накопление, обновление, обработка и хранение пространственных данных:

- цифровых растровых и векторных картографических материалов, в том числе ортофотопланов (М 1:500-1:50000);

- материалов инженерных, геодезических, экологических геологических и иных изысканий;

- сведений единого государственного реестра недвижимости, сведений о земельных отводах (проектируемых и предоставляемых земельных участках);

- сведений о градостроительном режиме территории (документах территориального планирования, правилах землепользования и застройки, проектах межевания и т.д.);

- сведений о границах и режиме зон с особыми условиями использования территорий (охранных, санитарно-защитных и др.);

- иные сведения о физических, экономических и правовых характеристиках и регламентах на территории муниципального образования.

Получив доступ к информационному ресурсу, пользователи системы одновременно получают полный набор инструментов по работе с информацией. 
Сравнительная характеристика геопорталов муниципальных образований

\begin{tabular}{|c|c|c|c|c|c|c|c|c|}
\hline Геопортал & $\begin{array}{l}\text { Качество карто- } \\
\text { графического } \\
\text { изображения }\end{array}$ & $\begin{array}{l}\text { Расширен- } \\
\text { ный поиск } \\
\text { по простран- } \\
\text { ственному } \\
\text { охвату (гра- } \\
\text { фическому } \\
\text { названию, } \\
\text { координа- } \\
\text { там) }\end{array}$ & $\begin{array}{l}\text { Администра- } \\
\text { тивно-террито- } \\
\text { риальное } \\
\text { устройство }\end{array}$ & $\begin{array}{l}\text { Адресный } \\
\text { реестр }\end{array}$ & $\begin{array}{l}\text { Кадастро- } \\
\text { вое деление }\end{array}$ & $\begin{array}{l}\text { Здания и } \\
\text { сооружения }\end{array}$ & $\begin{array}{l}\text { Использо- } \\
\text { вание зе- } \\
\text { мель }\end{array}$ & $\begin{array}{l}\text { Особо охра- } \\
\text { няемые тер- } \\
\text { ритории }\end{array}$ \\
\hline $\begin{array}{l}\text { Геопортал } \\
\text { г.Новоси- } \\
\text { бирска }\end{array}$ & $\begin{array}{l}\text { Среднее } \\
\text { (Яндекс Спутник, } \\
\text { Google Карта, } \\
\text { Google Спутник, } \\
\text { Bing Aerial, Bing } \\
\text { Roads) }\end{array}$ & + & $\begin{array}{l}\text { Кварталы, рай- } \\
\text { оны, округа. }\end{array}$ & - & $\begin{array}{l}\text { Зарегистри- } \\
\text { рованные } \\
\text { участки, } \\
\text { улицы, зда- } \\
\text { ния, допу- } \\
\text { стимое раз- } \\
\text { мещение } \\
\text { ОКС. }\end{array}$ & $\begin{array}{l}\text { Здания } \\
\text { (геофонд), } \\
\text { Зарегистри- } \\
\text { рованные } \\
\text { участки, } \\
\text { Кадастро- } \\
\text { вая стои- } \\
\text { мость 3У за } \\
1 \text { кв.м. }\end{array}$ & $\begin{array}{l}\text { с/х назна- } \\
\text { чения, } \\
\text { земли по- } \\
\text { селений, } \\
\text { земли про- } \\
\text { мышлен- } \\
\text { ности, } \\
\text { водного } \\
\text { фонда, за- } \\
\text { паса, лес- } \\
\text { ного } \\
\text { фонда. }\end{array}$ & - \\
\hline $\begin{array}{l}\text { Геопортал } \\
\text { г. Екате- } \\
\text { ринбурга }\end{array}$ & $\begin{array}{l}\text { Хорошеe } \\
\text { (GoogleMaps, } \\
\text { WikiMapia, OSM, } \\
\text { Фотоплан) }\end{array}$ & + & $\begin{array}{l}\text { Город, поселок, } \\
\text { село. }\end{array}$ & $\begin{array}{l}\text { Улицы, } \\
\text { про- } \\
\text { спекты, } \\
\text { площади и } \\
\text { т.п. }\end{array}$ & - & $\begin{array}{l}\text { Имуще- } \\
\text { ственные } \\
\text { торги, уста- } \\
\text { новка ре- } \\
\text { кламных } \\
\text { конструк- } \\
\text { ций, } \\
\end{array}$ & - & - \\
\hline $\begin{array}{l}\text { Геопортал } \\
\text { г. Якутска }\end{array}$ & $\begin{array}{l}\text { Хорошее } \\
\text { (OSM, 2Gis, Кoc- } \\
\text { моснимок, Адрес- } \\
\text { ный план, Росре- } \\
\text { естр) }\end{array}$ & + & $\begin{array}{l}\text { Город, районы, } \\
\text { сельские } \\
\text { округа, поселки } \\
\text { городского } \\
\text { типа. }\end{array}$ & $\begin{array}{l}\text { Улицы, } \\
\text { про- } \\
\text { спекты, } \\
\text { площади и } \\
\text { т.п. }\end{array}$ & - & $\begin{array}{l}\text { Аукционы } \\
\text { и торги, } \\
\text { установка } \\
\text { рекламных } \\
\text { конструк- } \\
\text { ций. }\end{array}$ & $\begin{array}{l}\text { Городские } \\
\text { леса, с/х } \\
\text { угодья, } \\
\text { производ- } \\
\text { ственного } \\
\text { назначе- } \\
\text { ния, }\end{array}$ & - \\
\hline
\end{tabular}


Продолжение таблиць

\begin{tabular}{|c|c|c|c|c|c|c|c|c|}
\hline Геопортал & $\begin{array}{l}\text { Качество карто- } \\
\text { графического } \\
\text { изображения }\end{array}$ & $\begin{array}{l}\text { Расширен- } \\
\text { ный поиск } \\
\text { по простран- } \\
\text { ственному } \\
\text { охвату (гра- } \\
\text { фическому } \\
\text { названию, } \\
\text { координа- } \\
\text { там) }\end{array}$ & $\begin{array}{l}\text { Администра- } \\
\text { тивно-террито- } \\
\text { риальное } \\
\text { устройство }\end{array}$ & $\begin{array}{l}\text { Адресный } \\
\text { реестр }\end{array}$ & $\begin{array}{l}\text { Кадастро- } \\
\text { вое деление }\end{array}$ & $\begin{array}{l}\text { Здания и } \\
\text { сооружения }\end{array}$ & $\begin{array}{l}\text { Использо- } \\
\text { вание зе- } \\
\text { мель }\end{array}$ & $\begin{array}{l}\text { Особо охра- } \\
\text { няемые тер- } \\
\text { ритории }\end{array}$ \\
\hline $\begin{array}{l}\text { Геопортал } \\
\text { г. Москвы }\end{array}$ & $\begin{array}{l}\text { Хорошее } \\
\text { (Топографиче- } \\
\text { ская, ЕГКО) }\end{array}$ & + & $\begin{array}{l}\text { Районы, посе- } \\
\text { ления, город- } \\
\text { ские округа. }\end{array}$ & $\begin{array}{l}\text { Улицы, } \\
\text { про- } \\
\text { спекты, } \\
\text { площади и } \\
\text { т.п }\end{array}$ & $\begin{array}{l}\text { Учтенные } \\
\text { ЗУ, Ранее } \\
\text { учтенные } \\
\text { ЗУ, } \\
\text { Временные } \\
\text { ЗУ. }\end{array}$ & $\begin{array}{l}\text { Изъятие } \\
\text { объектов }\end{array}$ & $\begin{array}{l}\text { Под про- } \\
\text { мышлен- } \\
\text { ными и } \\
\text { транс- } \\
\text { портными } \\
\text { сооруже-- } \\
\text { ниями }\end{array}$ & $\begin{array}{l}\text { Особо охра- } \\
\text { няемые зеле- } \\
\text { ные террито- } \\
\text { рии; } \\
\text { Природные и } \\
\text { озеленитель- } \\
\text { ные террито- } \\
\text { рии. }\end{array}$ \\
\hline $\begin{array}{l}\text { Геопортал } \\
\text { г. Санкт- } \\
\text { Питер- } \\
\text { бурга }\end{array}$ & $\begin{array}{l}\text { Хорошее } \\
\text { Обзорная карта } \\
\text { (от 1:300 } 000 \text { до } \\
1: 5000) ; \\
\text { Тематическая } \\
\text { карта (от 1:5 000). }\end{array}$ & + & $\begin{array}{l}\text { Районы, го- } \\
\text { рода-поселки, } \\
\text { водные объ- } \\
\text { екты, площад- } \\
\text { ные объекты, } \\
\text { муниципальные } \\
\text { образования, } \\
\text { базисные оси, } \\
\text { топонимы }\end{array}$ & $\begin{array}{l}\text { Геонимы } \\
\text { (улицы, } \\
\text { про- } \\
\text { спекты, } \\
\text { площади и } \\
\text { т.п); } \\
\text { Объекты } \\
\text { адресной } \\
\text { системы }\end{array}$ & $\begin{array}{l}\text { Кадастро- } \\
\text { вые квар- } \\
\text { тала, Ка- } \\
\text { дастровое } \\
\text { деление }\end{array}$ & $\begin{array}{l}\text { Проблем- } \\
\text { ные } \\
\text { участки } \\
\text { ИЖС }\end{array}$ & $\begin{array}{l}\text { ЗНОП } \\
\text { местного } \\
\text { значения, } \\
\text { ЗНОП го- } \\
\text { родского } \\
\text { значения }\end{array}$ & $\begin{array}{l}\text { Объекты } \\
\text { культурного } \\
\text { наследия; } \\
\text { Территории } \\
\text { объектов } \\
\text { культурного } \\
\text { наследия; } \\
\text { Зоны охраны; } \\
\text { Режимы зон } \\
\text { охраны объ- } \\
\text { ектов куль- } \\
\text { турного } \\
\text { наследия. }\end{array}$ \\
\hline
\end{tabular}


Окончание таблицьы

\begin{tabular}{|c|c|c|c|c|c|c|c|c|}
\hline \\
\hline Геопортал & $\begin{array}{l}\text { Качество карто- } \\
\text { графического } \\
\text { изображения }\end{array}$ & $\begin{array}{l}\text { Расширен- } \\
\text { ный поиск } \\
\text { по простран- } \\
\text { ственному } \\
\text { охвату (гра- } \\
\text { фическому } \\
\text { названию, } \\
\text { координа- } \\
\text { там) }\end{array}$ & $\begin{array}{l}\text { Администра- } \\
\text { тивно-террито- } \\
\text { риальное } \\
\text { устройство }\end{array}$ & $\begin{array}{l}\text { Адресный } \\
\text { реестр }\end{array}$ & $\begin{array}{l}\text { Кадастро- } \\
\text { вое деление }\end{array}$ & $\begin{array}{l}\text { Здания и } \\
\text { сооружения }\end{array}$ & $\begin{array}{l}\text { Использо- } \\
\text { вание зе- } \\
\text { мель }\end{array}$ & $\begin{array}{l}\text { Особо охра- } \\
\text { няемые тер- } \\
\text { ритории }\end{array}$ \\
\hline $\begin{array}{l}\text { Геопортал } \\
\text { г. Воро- } \\
\text { нежа }\end{array}$ & $\begin{array}{l}\text { Хорошее } \\
\text { (Изображение, } \\
\text { Яндекс Карта, } \\
\text { Google Гибрид, } \\
\text { Google Карта, } \\
\text { OpenStreetMap, } \\
\text { Топографическая- } \\
\text { карта, Космосни- } \\
\text { мок(2014г.), Циф- } \\
\text { ровая модель ре- } \\
\text { льефа, Фотограм- } \\
\text { метрическая обра- } \\
\text { ботка) }\end{array}$ & + & $\begin{array}{l}\text { Внутригород- } \\
\text { ские админи- } \\
\text { стративно-тер- } \\
\text { риториальные } \\
\text { единицы }\end{array}$ & $\begin{array}{l}\text { Улицы, } \\
\text { про- } \\
\text { спекты, } \\
\text { площади и } \\
\text { т.п. }\end{array}$ & $\begin{array}{l}\text { Кадастро- } \\
\text { вые квар- } \\
\text { талы }\end{array}$ & $\begin{array}{l}\text { Сведения о } \\
\text { многоквар- } \\
\text { тирных жи- } \\
\text { лых домах } \\
\text { и плановом } \\
\text { капиталь- } \\
\text { ном ре- } \\
\text { монте; } \\
\text { Площадки } \\
\text { жилищного } \\
\text { строитель- } \\
\text { ства. }\end{array}$ & $\begin{array}{l}\text { Под про- } \\
\text { мышлен- } \\
\text { ными и } \\
\text { транс- } \\
\text { портными } \\
\text { сооруже- } \\
\text { ниями }\end{array}$ & $\begin{array}{l}\text { Точечные, } \\
\text { полигональ- } \\
\text { ные }\end{array}$ \\
\hline
\end{tabular}


В ходе сравнения геопорталов нескольких городов РФ, видно, что не во всех городах наполненность геопортала отвечает принципам полноты информации, необходимой для его эффективной работы и предоставления пользователям необходимой информации. Из проведенного анализа геопорталов, самым полным из приведенных является геопортал города Санкт-Петербурга. Сведения, размещаемые на геопортале, обновляются с заданной периодичностью и являются наиболее полными.

Исходя из анализа, можно сказать, что геопортал Новосибирска не полной и исчерпывающей информации о территории.

Таким образом, следует отметить, что на сегодняшний день далеко не все муниципальные образования используют подобные геоинформационные системы, поскольку их внедрение и дальнейшее обслуживание является довольно дорогостоящими. Вместе с тем, внедрение подобных систем позволит органам местного самоуправления максимально автоматизировать процессы предоставления муниципальных услуг, повысит качество управления муниципальной территорией, снизит трудозатраты на многие операции, выполняемые сотрудниками органов местного самоуправления.

Важным условием для создания эффективного геопортала является наличие качественной геодезической и картографической основы.

В качестве цифровой картографической основы возможно использование разнородных цифровых картографических материалов, которые будут объединены в единую мультимасштабную цифровую карту. В качестве элементов могут выступать различные WEB-геосервисы (для ориентирования объектов), топографические (в том числе дежурные) планы масштаба 1:500 1:2000, а также в качестве обязательного элемента - ортофотопланы высокой точности.

\section{БИБЛИОГРАФИЧЕСКИЙ СПИСОК}

1. Анисимова О.Л., Пестов И.Д., Серебряков С.В. . Информационное и программное обеспечение управления метаданными на базе регионального центра Уральского федерального округа // Пространственные данные. - 2015. - № 2 [Электронный ресурс] Режим доступа: http://gisa.ru/54644.html.

2. Бездушный А.Н., Вершинин А.В., Динь Ле Дат. Пространственные метаданные в системе «ГеоМЕТА» // Пространственные данные. - 2008. - № 2. [Электронный ресурс] Режим доступа: http://gisa.ru/45988.html.

3. Геопортал города Новосибирска [Электронный ресурс] Режим доступа: http://gis.novosibirsk.ru.

4. Геопортал города Екатеринбурга [Электронный ресурс] Режим доступа: https://геопортал.екатеринбург.рф.

5. Геопортал города Санкт-Питербурга [Электронный ресурс] Режим доступа: https://portal.kgainfo.spb.ru.

6. Геопортал города Воронежа [Электронный ресурс] Режим доступа: https://map.govvrn.ru.

7. Геопортал города Москвы [Электронный ресурс] Режим доступа: https://isogd.mos.ru. 
8. Геопортал города Якутска [Электронный ресурс] Режим доступа: https://map.yakadm.ru.

9. Якубайлик О.Э. Картографические веб-приложения и сервисы Красноярского геоинформационного портала СО РАН. - В кн.: Геоинформационные технологии и математические модели для мониторинга и управления экологическими и социальноэкономическими системами: / ред. кол.: Ю.И. Шокин [и др.]; под ред. И.Н. Ротановой; Рос. акад. наук, Сиб. отделение, Ин-т водных и экологич. проблем. - Барнаул: Пять плюс, 2011. - С. 94-100.

(C) Е. Д.Соловьева, Н. О. Митрофанова, 2021 